\title{
BODY COMPOSITION AND THE SOMATOTYPE OF EUROPEAN TOP ROLLER SPEED SKATERS
}

\author{
Martin Matyk, Christoph Raschka \\ Hessian and German Roller Sports and Inline Association \\ Institute of Sports Sciences, Julius-Maximilians-University, Germany
}

\begin{abstract}
The purpose of this study was to examine the differences between the body types of roller speed skaters. We started from the question of whether there is a roller speed skating type and which may be the most important constitutional conditions.

To this end, the authors of this work made use of the constitution typologies of Conrad, Knußmann, Tittel and Wutscherk, Parnell, Heath and Carter, and the proportion figures. The skin fold thickness measurement, the bioelectrical impedance analysis, the active substancebody and body-mass index were additionally involved in determining body composition.

A total of 45 people were surveyed: the most successful male and female European roller speed skaters. Of these, 22 were sprinters and 23 long-distance speed skaters. The average age of the sprinters was 22.5 years $(\mathrm{sd}=3.5$ years $)$ and long-distance speed skaters 22.3 years $(\mathrm{sd}=$ 2.6 years). For comparison, 49 students with an average age of 20.5 years $(\mathrm{sd}=3.5)$ were used as control group.

According to the typology of Knußmann, roller speed skaters may be classified as leptomorph. The students in the control groups and the sprinters tend to a larger and heavier body growth on average than the long-distance speed skaters.
\end{abstract}

From the gathered data an athletic body weight stands out significantly $(\mathrm{p} \leq 0.001)$ lighter in speed skaters compared to the control groups. Within the study group the long-distance speed skaters show the lowest body weights, followed by the sprinters and the control groups.

The present study suggests that a European roller speed skater of the elite class is built smaller, more athletic and lighter than the comparison subjects of the collective. But, of course, there will always be found the 
athletes who do not comply with the found body data, yet they are successful in European or World Championships. Based on the collected data, there are clues to a particular type of constitution in roller speed skating.

Key words: Sports Anthropology, Sports Anthropometry, Inline Speed Skating, Roller Speed Skating, Speed skating, Body Composition, Body Fat.

\section{INTRODUCTION}

Roller skating is a popular trend sport worldwide. Derived from the ice skates, roller skates have spread all over the world in the nineties. Roller speed skating, a form of roller sports, is a popular as well as a competitive sport. Every year, European and World Championships are being conducted in this sport, and the titles are redistributed every time. But what makes a roller speed skater successful? What are the best conditions to maximize individual performance? Is there a relationship between athletic performance and physique? Top performances in sports can only be provided if the athlete is able to achieve the physical, mental and social conditions and combine them with advanced training.

The central question of this study is to what extent there is a roller speed skating type and which might be the important constitutional requirements for such a type. Furthermore, the question will be expanded to see if there are type-dependent differences within the disciplines of competition.

Not only the results could be of great importance for talent scouting, they could also make an important contribution to the optimization of training management and planning. Individual deficits in body composition could be identified and treated.

\section{METHODS}

For this study sports anthropometrical data of the most successful European roller speed skaters were collected. For this purpose, 45-line speed skaters $(\mathrm{m}=26, \mathrm{f}=19)$ were compared with 49 subjects in the control group $(\mathrm{m}=28, \mathrm{f}=21)$. The speed skaters were subdivided by successes in short or long-distance, long-distance skaters or sprinters. 
The entire collective consists of 94 participants, divided into 54 male and 40 female. The youngest respondent was 18 years old and the oldest was 32 years old. The average age was 21 years. All the subjects volunteered for the anthropometric study and presented their data anonymously for this work.

The anthropometric study took place at the European championships in Speed Skating, July 29 through August 8, 2009 in Ostend, Belgium. All the male and female roller speed skaters were exclusively national team athletes from Europe. The fact that all the athletes were in a competition period ensured that they were in the best possible training conditions. Only the data of the best European skaters (Top 8) was used. Among the subjects, there were multiple European and World Champions. Depending on the discipline and success, the athletes were divided into long-distance skaters or sprinters.

\section{ANTHROPOMETRIC MEASURES}

The anthropometry data in this work correspond to the international standard $[10,11]$ and were completed by the authors of this study. The provisions of body weight and bioelectrical impedance analysis (BIA) of the subjects were measured on a calibrated scale. Heights and arm span were measured with the anthropometrical measurements. Length and width dimensions were measured with the small and large calipers. To determine the body circumferences, a commercially available tape measure was used. The skinfolds were measured with a caliper of the company Siber Hegner. The results were statistically checked by means of ANOVA.

Knußmann [8], with the help of the discriminant analysis, developed an objective method of determining body types for the leptomorphpyknomorph primary set of variations of Conrad. The exactly defined landmarks after Knussmann [8] were conduced as the foundation of the examined and calculated measures.

Conrad developed a checkerboard-like coordinate system in which he contrasts the typology of a hyper sculptor (athletics) with the hypoplastic (asthenic). He combines the hypoplastic-hyperplastic variation series with the leptomorph-pyknomorph set of variations [14, $15]$. 
Parnell $[12,13]$ and Heath and Carter [6, 7], developed a three digit index, with which they exactly describe the somatotypes. They divide the human physique into three body types: ektomorph, mesomorph and endomorph, each of which individually is divided into seven different degrees of severity. The first number of the triple describes the fat factor (endomorphy) of the subjects. It is calculated by Parnell $[12,13]$ from the sum of skinfolds ( $\mathrm{mm}$ ) from HFF triceps, subscapular-HFF, HFFsuprailiacal and age. The second figure of the triple shows the combined muscle and roughness factor (mesomorphy) and the third a factor of linearity (ektomorphy).

\section{RESULTS}

The observations of the body data of all the tested groups are summarized in Table 1. The long distance roller speed skaters show the smallest percentage of body fat (BIA, Caliper), height, mass, BMI and Broca Index data of all participants for gender specific and investigation-specific data. The control groups and the sprinters tend on average to a larger and heavier body growth than the long distance skaters.

According to Knußmann the body typognose of the male and female roller speed skaters can be classified as leptomorph (Figure 1,2). It can be assumed that the long-distance skaters tend to leptomorphy more than the control group. In the second set of variations (macrosomia / microsomia) all the subjects show some macro values. It seems that the long-distance skaters tend to be the smallest subjects, while the sprinters appear slightly larger. The largest bodies tend to have the people of the control group as they have the highest data on average. The factor category of all the subjects affects the first set of variations (leptomorphy / pyknomorphy) very significantly and to the second set of variations (microsomia / macrosomia) highly significant.

According to the constitution typology of Conrad all male and female long-distance skaters in Figure 5 are exclusively on the leptomorph side. The athletes tend to the metro-dimensional leptomorph direction. 
Table 1. Results of body composition data of all the examined groups

\begin{tabular}{|l|c|c|c|c|c|c|c|}
\hline & $\begin{array}{c}\text { Long } \\
\text { Distance } \\
\text { male }\end{array}$ & $\begin{array}{c}\text { Short } \\
\text { Distance } \\
\text { male }\end{array}$ & $\begin{array}{c}\text { Control } \\
\text { group } \\
\text { male }\end{array}$ & $\begin{array}{c}\text { Long } \\
\text { Distance } \\
\text { female }\end{array}$ & $\begin{array}{c}\text { Short } \\
\text { Distance } \\
\text { female }\end{array}$ & $\begin{array}{c}\text { Control } \\
\text { group } \\
\text { female }\end{array}$ & p \\
\hline (n) & 12 & 14 & 28 & 11 & 8 & 21 & n.s. \\
\hline Age (yrs) & 21.7 & 23.0 & 21.3 & 23.0 & 21.6 & 19.5 & n.s. \\
& $(2.3)$ & $(3.9)$ & $(3.8)$ & $(2.7)$ & $(2.6)$ & $(2.9)$ & \\
\hline Height (cm) & 174.8 & 177.3 & 180.4 & 159.9 & 166.0 & 169.6 & n.s. \\
& $(5.6)$ & $(5.9)$ & $(5.9)$ & $(3.9)$ & $(5.0)$ & $(7.0)$ & \\
\hline Mass (kg) & 68.9 & 73.2 & 75.7 & 52.8 & 58.3 & 64.8 & $\leq 0.001$ \\
& $(6.3)$ & $(7.5)$ & $(10.0)$ & $(4.8)$ & $(2.1)$ & $(13.1)$ & \\
\hline BIA-Fat & 8.0 & 8.1 & 15.3 & 17.7 & 20.8 & 24.5 & n.s. \\
$(\mathbf{( \% )}$ & $(1.9)$ & $(3.0)$ & $(6.9)$ & $(4.0)$ & $(2.3)$ & $(5.7)$ & \\
\hline Caliper-Fat & 11.0 & 9.7 & 17.8 & 17.5 & 17.6 & 24.8 & n.s. \\
$(\mathbf{( \% )}$ & $(2.1)$ & $(2.0)$ & $(6.5)$ & $(2.2)$ & $(1.0)$ & $(4.9)$ & \\
\hline Broca Index & 92.0 & 94.7 & 94.6 & 98.0 & 98.5 & 103.2 & n.s. \\
& $(5.4)$ & $(6.1)$ & $(14.2)$ & $(7.5)$ & $(6.1)$ & $(15.2)$ & \\
\hline BMI & 22.5 & 23.2 & 23.3 & 20.6 & 21.2 & 22.4 & n.s. \\
(kg/m $\left.^{2}\right)$ & $(1.3)$ & $(1.5)$ & $(3.4)$ & $(1.5)$ & $(1.0)$ & $(3.4)$ & \\
\hline
\end{tabular}

The results of this work show that the somatocharts that were found have similar results according to Parnell or Heath and Carter (Figure 3, 4). The results by Heath and Carter show that the male speed skaters tend more to the ecto-mesomorphic somatotype. The female roller speed skaters are in the central area, with a slight tendency to the endomesomorphic direction. It turns out that women are generally more endomorph and less mesomorph than men.

Compared to the younger people of the control group, the considerations of the typology of Conrad and the somatocharts of Parnell, and Heath and Carter showed no significant differences on average, but they tended strongly in the direction of the typognose by Knußmann. 


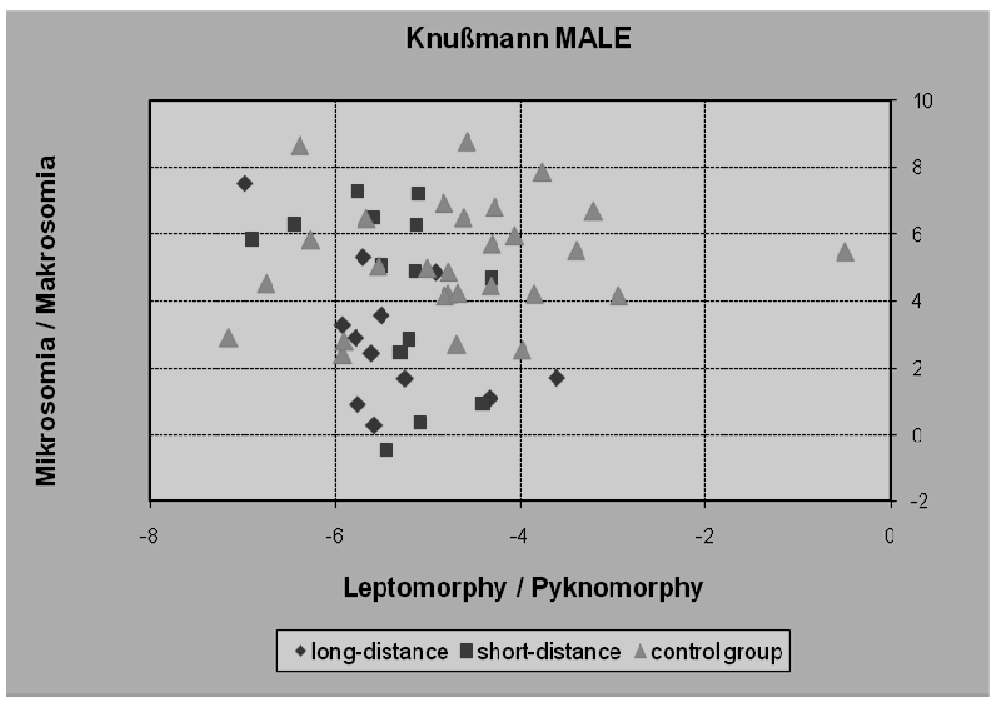

Figure 1. System of the male constitution types after Knußmann.

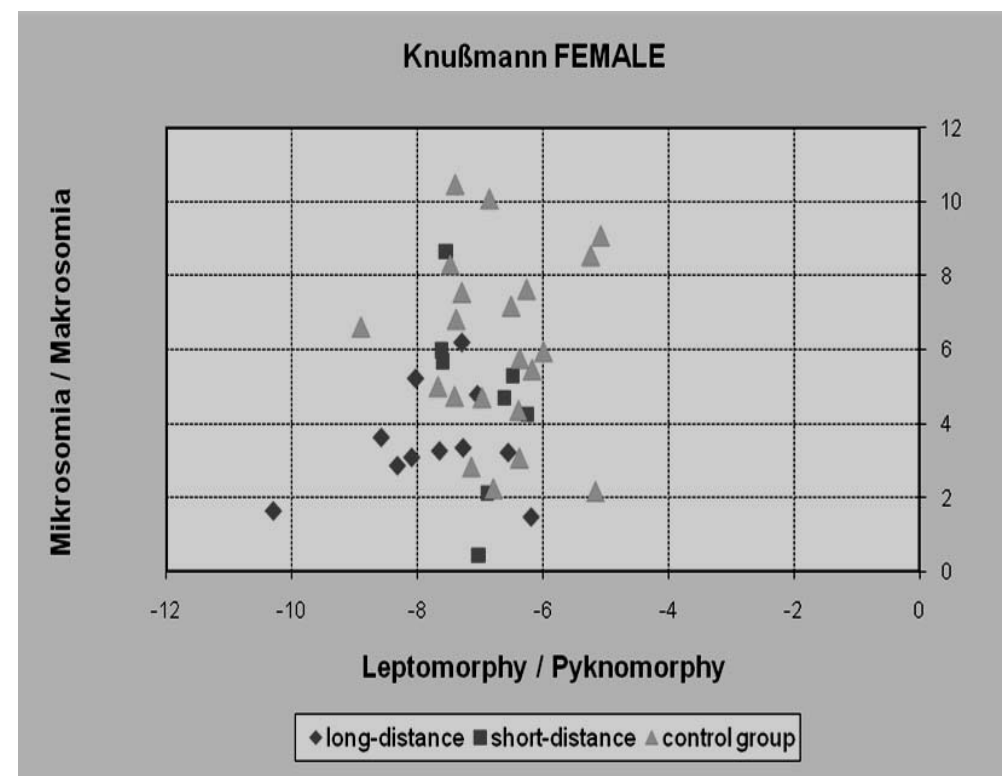

Figure 2. System of the female constitution types after Knußmann. 
- long-distance

$\Delta$ short-distance

- control group

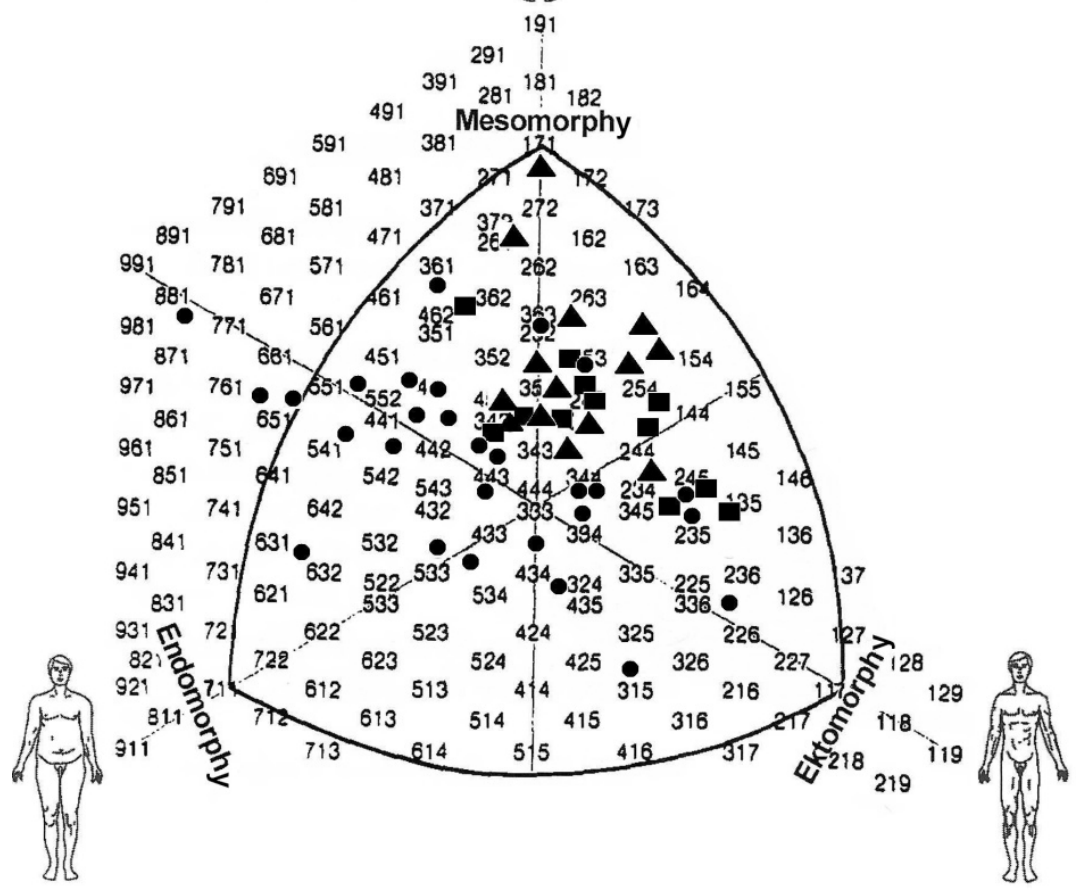

Figure 3. Somatochart after Heath and Carter of the male group. 
- long-distance

$\Delta$ short-distance

- control group
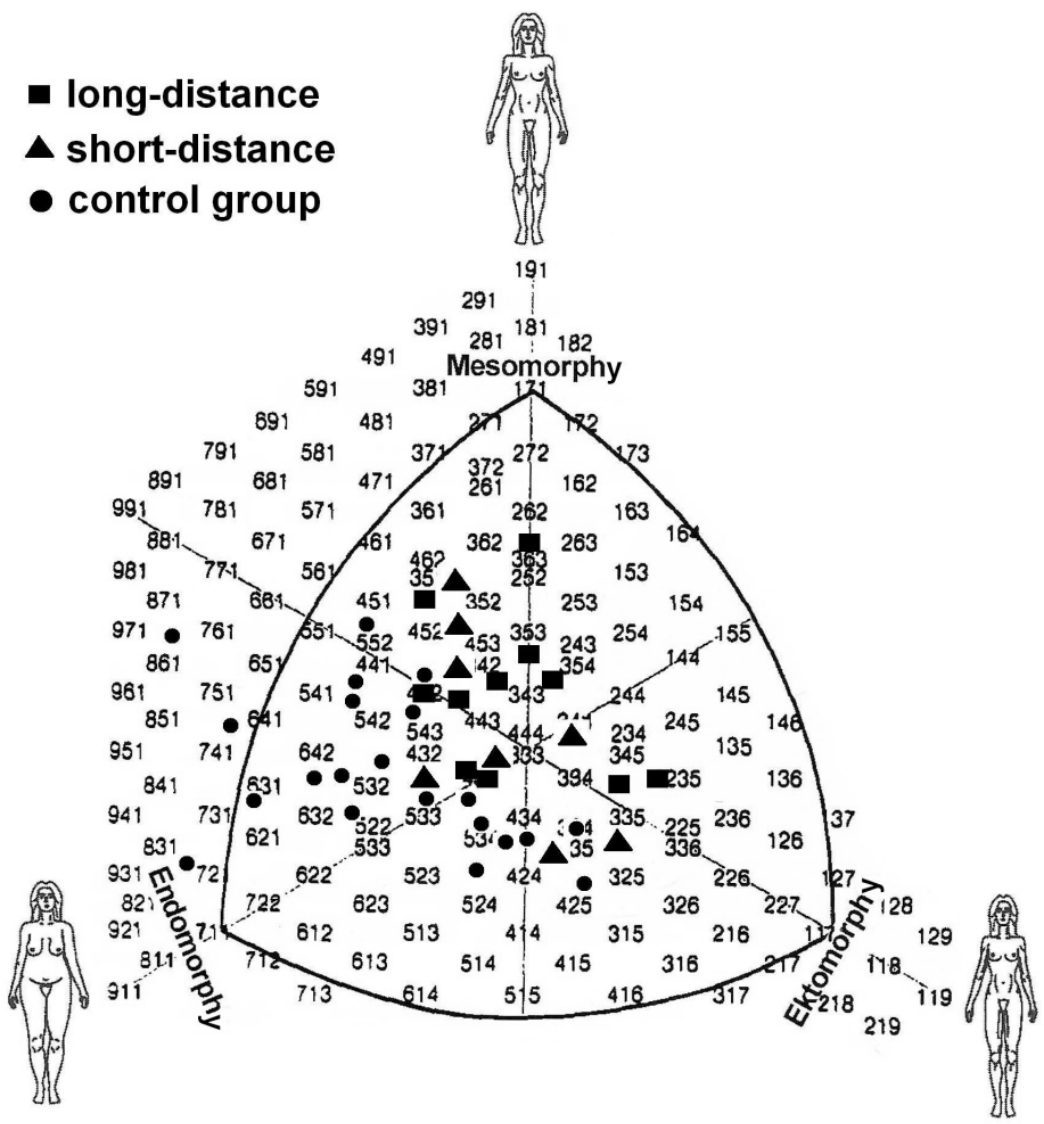

Figure 4. Somatochart after Heath and Carter of the female group. 

$A=$ long-distance male
$D=$ long-distance female
$\mathbf{B}=$ short-distance male
$E=$ short-distance female
$\mathbf{C}=$ control group male
$\mathbf{F}=$ control group female

\section{leptomorph}

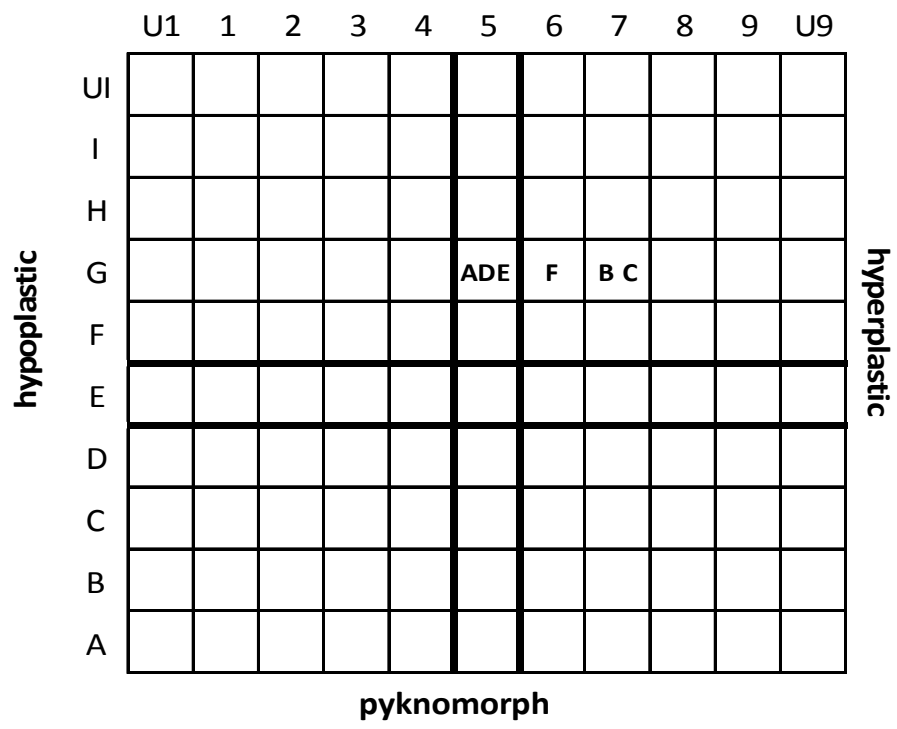

Figure 5. Chessboard pattern graphic after CONRAD with the average of both genders and disciplines.

\section{DISCUSSION}

The results of body height show a tendency to the effect that the most successful European roller speed skaters in 2009, are smaller on average than the control groups and the men larger than the women. The average height is $174.8 \mathrm{~cm}$ in the male long-distance skaters, $177.3 \mathrm{~cm}$ in the sprinters and $180.4 \mathrm{~cm}$ in the control group. Among the female longdistance skaters women have an average height of $159.9 \mathrm{~cm}$, the sprinters are slightly larger with $166 \mathrm{~cm}$ and the subjects of the control group are with $169.6 \mathrm{~cm}$ the largest. The results are not significant 
$(\mathrm{p}>0.05)$, but it is possible that the average European roller speed skater tends to be smaller than the normal European citizen.

Highly significant differences in body weight were displayed $(\mathrm{p} \leq 0.001)$ among the various categories. The male and female longdistance skaters show the lowest weight, followed by the sprinters and then the subjects in the control groups. In male subjects the longdistance skaters weigh $68.9 \mathrm{~kg}$ on average, the sprinters $73.2 \mathrm{~kg}$ and the control group $75.7 \mathrm{~kg}$. In the female category the long-distance skaters are the lightest with $52.8 \mathrm{~kg}$ on average, followed by the sprinters with $58.3 \mathrm{~kg}$. The subjects in the control group have the highest body weight $64.8 \mathrm{~kg}$. The men are heavier and taller on average than the women.

Among the speed skaters the long-distance athletes tend to have the lowest height and weight. This may be related to the requirements of the athlete. A long-distance skater who is to contest in an endurance distance on a $200 \mathrm{~m}$ track has to be able to move as economically as possible. The centrifugal forces in a curve are higher on the body the heavier the athlete is.

The larger and heavier the athlete, the more weight he has to move and the more force he has to raise per push. In the sum of a distance a large and heavy speed skater has to spend more energy than a smaller and lighter athlete. Bernhard \& Jung [1] confirm the assumption that for the same physical strain a large runner requires up to 25 per cent more energy than a smaller one. If we transfer this to roller speed skating, a larger athlete has to train more for the same amount of power than a smaller one. Otherwise his competitive performance might very likely be lower.

A short statured roller speed skater has agility benefits in the speed of movement and action. Among the speed skaters it is extremely important that they will not only adapt to situations quickly and react to them, but also that they can perform quickly. On the other hand, a taller speed skater may have benefits on a road course. Because of the longer legs the athlete can increase his phase of pushing. Consequently, he does not have to take as many steps as a small speed skater and would thus save energy.

Because of the results of the fat data (BIA, caliper), it is to assume that the strength training important for the speed skating sprinter leads to adaptation with a reduction of subcutaneous fat and increased muscle 
mass [18]. For the long-distance skaters the slightly higher fraction of fat needs not be a performance-limiting reason.

Like a sprinter, a long-distance skater has to be able to move quickly, but because of the longer race distance he has more time to get to high speeds. A sprinter has to reach his top speed in no time [2], so too much subcutaneous fat would be dead weight and thus counter-productive in both categories. Possibly because of a lack of movement and fitness, the people in the control groups show higher data, although there are exceptions.

Among the female subjects both categories of women speed skaters show almost identical fat values on average. This suggests that the female roller speed skaters show no difference in fat content and possibly in the requirements.

By the results after Knußmann it can be assumed that the speed skaters tend more to leptomorphy than the control group. The roller speed skater appears rather thin and athletic, which helps him to meet his requirements. The long-distance skaters seem to tend to be the smallest subjects on average (3.0), while the sprinters appear slightly larger (4.3). The male control group tends to have the largest body, with the highest average (5.2). It can be assumed that the speed skater group tends to a thinner and smaller physique compared to the control group.

The female athletes present themselves through their superleptomorph and ultra macrosomic data as athletic, thin and small people, compared to the control group. Here it is clear that in roller speed skating the proportion and size factor plays a role and the athletic training of body shapes has an important meaning for the speed skating performance.

The results according to Heath and Carter support these statements. The requirement of all the speed skaters is characterized by the increased physical strain and sports specific movements in the lower extremities $[3,4]$. The average data of mesomorphy of the roller speed skaters reflects the tendency for higher muscle mass. The slight tendency to ektomorphy clearly shows that the skaters, in contrast to endomorphy, are rather narrow and slender.

For men it seems to be important to have a strong and powerful but also light body. Although power increases with additional muscle mass, so does the body weight. The male speed skaters weigh $71.2 \mathrm{~kg}$ on average. The results show that the male speed skater tends more to the 
ecto-mesomorphic somatotyp. A highly trained mesomorphy appears to be less limiting for sprinters than for long-distance skaters.

For the long-distance skaters it is important both to be light for the endurance, as well as possessing enough power and speed for intermediate and final sprints. For the required pace hardness in international competitions it is crucial to meet these requirements. The body constitutions may limit these benefits, so that no large and heavy longdistance skaters can successfully establish themselves among the international leaders.

The average of both male speed skating categories is located in the ecto-mesomorphic range. The female roller speed skaters tend to have a slight tendency in the endo-mesomorphic direction. It is not safe, however, to determine a specific somatotype with them, because the female athletes, as opposed to men, are distributed among all the areas of the somatocharts.

From this it can be interpreted that for women the human physique needs not be a limiting factor for the success in roller speed skating. Obviously, a higher portion of subcutaneous fat is not giving them any substantial disadvantage. It turns out that women are generally more endomorph and less mesomorph than men. The reason for this, according to Gualdi Russo et al. [5], lies in the female genetics, which by nature are directed to gender specific functions. Furthermore, the endomorphy data correlate negatively with physical fitness [7]. This might also be the cause for the data of the control groups.

By results according to CONRAD, all the long-distance skaters and even the female sprinters are mainly on the leptomorphic side. The longdistance skaters show up as lean, muscular types of medium height. These constitutional features are probably also related to the requirements in the category of athletes. For a speed skater, it is important not to have a high body weight, because he often has to race long distances and in the curves of a track he will be confronted with the law of centrifugal force [9]. Radius, speed and weight determine the centrifugal force of the curve of routing. The small, slim and light body structure meets the requirements of the long-distance skater and proves to be an advantage in practice and competition. The requirements of good female long-distance skaters seem to coincide with that of the sprinters. Most female athletes take part in both competitions, in the short as well as in the long distances. 
With the same leptomorphy shape, the male speed skating sprinters and the control group are both in the average of an increasingly hyperplastic type. It is expected that the athlete is built a little stronger and taller on average. Body mass and the size do not seem to be as limiting under competitive conditions and training requirements as with the long-distance skaters. Nevertheless, the sprinters have to move more mass in competition or training, but in a shorter distance and exposure time.

Comparing the male study groups among themselves, it is striking that the groups do not differ greatly on average. The sprinters are in the same coordinate field (G 7) with the control group and next to them are the long-distance skaters (G 5). The speed skaters have manifested no significant differences in the coordinate field. In this study sample according to CONRAD no clear type of a speed skater can be revealed.

As a result of the present study it can be assumed that a European roller speed skater of the elite class is built smaller, more athletic and lighter than the comparison subjects of the collective. Based on the collected data, there are clues to a particular type of constitution in roller speed skating.

\section{REFERENCES}

1. Bernhard W. \& Jung K. (1998) Sportanthropologie. Gustav Fischer Verlag, Stuttgart, Jena, Lübeck, Ulm.

2. De Koning JJ, de Groot G, van Ingen Schenau GJ (1992) A power equation for the sprint in speed skating. J Biomech 25, 573-580.

3. De Boer, R. W., G. Ettema, H. van Gorkum, G. de Groot, G. J. van Ingen Schenau (1987) Biomechanical Aspects of Push-off Techniques in Speed Skating in Curves. International Journal of Sport Biomechanics, 3: 69-79.

4. De Boer, R. W., W. Hutter, G. de Groot, G. J. van Ingen Schenau (1987) Physiological and Biomechanical Comparison of Roller Skating and Speed Skating on Ice. European Journal of Applied Physiology, 56, 5: 562-569.

5. Gualdi Russo E., Gruppioni G., Gueresi P., Belcastro M. \& Marchesini V. (1992) Skinfolds and body composition of sports participants, the Journal of Sports Medicine and Physical Fitness, Vol. 32, Nr. 3, S. 303313. 
6. Heath B. \& Carter J. (1967) A modified somatotype method, American Journal of Physical Anthropology, Vol. 27, Nr. 57, S. 57-74.

7. Heath B. \& Carter J. (1990) Somatotyping - development and application, Cambridge University Press, Cambridge.

8. Knußmann R. (1996) Vergleichende Biologie des Menschen: Lehrbuch der Anthropologie (2. Auflage). Gustav Fischer Verlag, Stuttgart.

9. Marcelloni, P. (2007) Die Technik des Inline-Skatings. Kennenlernen, erwerben, unterrichten. Aus dem Italienischen von Ruedi Wenger. Jesi (Italien), Editrice Stampa Nova.

10. Martin R. \& Knußmann R. (1988) Anthropologie, Handbuch der vergleichenden Biologie des Menschen, Band I, Gustav Fischer Verlag, Stuttgart.

11. Martin R. \& Saller K. (1957) Lehrbuch der Anthropologie (3. Auflage). Fischer Verlag, Stuttgart.

12. Parnell, R. W. (1954) Somatotyping by physical anthropometry. Am.J.Phys.Anthrop. 12, 209-210.

13. Parnell R. (1958) Behaviour and physique, Arnold, London.

14. Raschka C. (1995) Körperbau-Konstitutionstypen in der naturwissenschaftlichen Anthropologie, Ärztezeitschrift für Naturheilverfahren, Heft 10, 36. Jahrgang, S. 759-782.

15. Raschka C. (2006) Sportanthropologie. Leitfaden der modernen, vergleichenden Sportanthropologie, Sportanthropometrie und trainingsrelevanten Konstitutionsbiologie. Sportverlag Strauß, Köln.

16. Conrad K. (1963) Der Konstitutionstypus. Springer Verlag, Berlin.

17. Carter J.E.L., Heath B.H. (1990) Somatotyping development and applications. Cambridge.

18. Sovak D, Hawes MR. (1987) Anthropological status of international calibre speed skaters. University of Calgary, Alberta, Journal of Sports Sciences 5 (3), 287-304.

\section{Address for correspondence:}

Martin Matyk

Julius-Maximilians-University

Hessian and German Roller Sports and Inline Association Institute of Sports Sciences

Stiftstraße 18, 64367 Mühltal, Germany

E-mail: matyk@gmx.de 